\title{
Sternocleidomastoid muscle activation following inspiratory muscle training in patients with chronic obstructive pulmonary disease: a randomized clinical trial
}

Ativação do músculo esternocleidomastoideo após treinamento muscular inspiratório em pacientes com doença pulmonar obstrutiva crônica: ensaio clinico randomizado

Activación del músculo esternocleidomastoideo tras el entrenamiento muscular inspiratorio de pacientes con enfermedad pulmonar obstructiva crónica: un ensayo clinico aleatorizado

Diogo Fanfa Bordin', Dannuey Machado Cardoso², Litiele Evelin Wagner³ ${ }^{3}$ Paula Regina Beckenkamp ${ }^{4}$, Andrea Lúcia Gonçalves da Silva ${ }^{5}$, Dulciane Nunes Paiva ${ }^{6}$

\begin{abstract}
This study aims to assess the effect of shorttime low frequency inspiratory muscle trainer (Threshold IMT) on inspiratory muscle strength and electromyographic activity of the sternocleidomastoid (SCM) muscle in people with chronic obstructive pulmonary disease (COPD). People with COPD participating in a lung rehabilitation program were allocated to a control or inspiratory muscle training (IMT) group. The control group participated in the usual rehabilitation, whereas the other group received IMT (performed with a load of 50\% maximal inspiratory pressure (MIP) adjusted weekly). Both interventions lasted for 2 months. Outcomes included electromyographic analysis of the SCM and MIP. In total, ten participants were allocated to each group. The IMT group presented an increase in absolute $(p<0.001)$ and predicted $(p<0.001)$ values of MIP and also in pre- and post-intervention variation between groups ( $p=0.003$ and $p=0.008$, respectively). Such differences were not found in the control group. The SCM muscle activity decreased in the IMT post intragroup evaluation ( $p=0.008$ ). IMT provided a reduction of the electromyographic activity of SCM in COPD patients, also increasing inspiratory muscle strength in the study participants.
\end{abstract}

Keywords | Electromyography; Respiratory Muscles; Pulmonary Disease, Chronic Obstructive; Respiratory Terapy.

RESUMO I O objetivo deste estudo foi avaliar o efeito do treinamento muscular inspiratório de baixa frequência de curta duração (Threshold TMI) na força muscular inspiratória e na atividade eletromiográfica do músculo esternocleidomastoideo (ME) em pessoas com doença pulmonar obstrutiva crônica (DPOC). Pessoas com DPOC que participam de um programa de reabilitação pulmonar foram alocadas em um grupo controle ou de treinamento muscular inspiratório (TMI). O grupo controle participou da reabilitação habitual, enquanto o grupo TMI também recebeu TMI, com carga de $50 \%$ da pressão inspiratória máxima (PImáx) ajustada semanalmente. Ambas as intervenções duraram 2 meses. Os resultados incluíram análise eletromiográfica do SCM e PImáx. Dez participantes foram alocados para o grupo controle e 10 para o grupo TMI. O grupo com TMI apresentou um aumento na PImáx nos valores absoluto $(p<0,001)$ e previsto $(p<0,001)$ e na variação pré e pós-intervenção entre os grupos

Study conducted at Pulmonary Rehabilitation Program of Hospital of Santa Cruz do Sul, Santa Cruz do Sul (RS), Brazil. 'Universidade de Santa Cruz do Sul (Unisc) - Santa Cruz do Sul (RS), Brazil. E-mail: diogo.fanfa@hotmail.com. Orcid: 0000-0003-1056-5155 2Universidade Federal do Rio Grande do Sul (UFRGS) - Porto Alegre (RS), Brazil. E-mail: dannuey@yahoo.com.br. Orcid: 0000-0003-2891-1028

3Universidade de Santa Cruz do Sul (Unisc) - Santa Cruz do Sul (RS), Brazil. E-mail: liti_wagner95@hotmail.com. Orcid: 0000-0002-3727-5732

${ }^{4}$ University of Sydney - Sydney, Australia. E-mail: paulabeckenkamp@sygney.edu.au. Orcid: 0000-0003-3986-6111

5Universidade de Santa Cruz do Sul (Unisc) - Santa Cruz do Sul (RS), Brazil. E-mail: andreag@unisc.br. Orcid: 0000-00028893-286x

6Universidade de Santa Cruz do Sul (Unisc) - Santa Cruz do Sul (RS), Brazil. E-mail dulciane@unisc.br. Orcid: 0000-0001-5629-3285 
( $p=0,003$ e $p=0,008$, respectivamente). Tais diferenças não foram encontradas no grupo controle. A atividade muscular do ME diminuiu no TMI após avaliação intragrupo $(p=0,008)$.

O TMI proporcionou redução da atividade eletromiográfica do ME em pacientes com DPOC, além de aumentar a força muscular inspiratória nos participantes do estudo.

Descritores | Eletromiografia; Músculos Respiratórios; Doença Pulmonar Obstrutiva Crônica; Terapia Respiratória.

RESUMEN | El presente estudio tuvo como objetivo evaluar el efecto del entrenamiento muscular inspiratorio de baja frecuencia a corto plazo (Threshold TMI) sobre la fuerza muscular inspiratoria y la actividad electromiográfica del músculo esternocleidomastoideo (ME) en personas con enfermedad pulmonar obstructiva crónica (EPOC). Las personas con EPOC que participan en un programa de rehabilitación pulmonar se asignaron a un grupo control o de entrenamiento muscular inspiratorio (EMI). El grupo control participó en la rehabilitación habitual, mientras que el grupo de EMI también recibió EMI, con una carga del 50\% de la presión inspiratoria máxima (PImáx) ajustada semanalmente. Ambas intervenciones tuvieron 2 meses de duración. Los resultados incluyeron el análisis electromiográfico de SCM y PImáx. Se asignaron 10 participantes al grupo control y 10 al grupo de EMI. El grupo de EMI tuvo un aumento de la PImáx en los valores absoluto $(p<0,001)$ y predicho $(p<0,001)$ y en la variación pre y posintervención entre grupos ( $p=0,003$ y $p=0,008$, respectivamente). No se encontraron estas diferencias en el grupo control. La actividad muscular del ME disminuyó en el EMI después de la evaluación intragrupal ( $p=0,008$ ). El EMI redujo la actividad electromiográfica del ME de pacientes con EPOC, además aumentó la fuerza muscular inspiratoria en los participantes del estudio.

Palabras clave | Electromiografía; Músculos Respiratorios; Enfermedad Pulmonar Obstructiva Crónica; Terapia Respiratoria.

\section{INTRODUCTION}

Chronic obstructive pulmonary disease (COPD) is a systemic condition characterized by airflow limitation, being not fully reversible ${ }^{1}$. Pulmonary hyperinflation, which is an abnormal increase on functional residual capacity (i.e., lung volume at the end of tidal expiration), induces the recruitment of inspiratory accessory muscle, which can fatigue the muscles involved $^{2}$. The diaphragm is the most affected muscle, as it becomes flattened, reducing its motion and efficiency to contract. Structural changes in the thoracic cage caused by the overload of diaphragm increase the resistance to fatigue $\mathrm{e}^{3-5}$. However, it does not increase inspiratory pressure, leading to accessory muscle activation to compensate the increase in ventilation demand ${ }^{3}$, including the activation of the scalene and sternocleidomastoid (SCM) muscles ${ }^{3}$.

The diagnosis of respiratory muscles disorders is commonly confirmed by respiratory muscle strength tests, using maximal respiratory pressure ${ }^{6}$. However, this method only enables a global assessment, without differentiating the muscle groups involved ${ }^{6}$. Surface electromyography (EMG) is a non-invasive technique that allows differentiation of muscle activity generated in different muscle groups, assessing muscle activation by electric signals, and it has been used under different conditions ${ }^{4-7}$.

Inspiratory muscle training (IMT) enables effective increments in respiratory muscle loading, and it can be conducted by spring-loaded valves such as the threshold inspiratory muscle trainer (Threshold IMT) ${ }^{8}$, or by incentive spirometers or other devices ${ }^{9}$. Although spring-loaded valve devices are superior for inspiratory muscle training - as it produces a linear pressure load enabling gradual pressure increments, so that strength gains are proportional to the resistance applied ${ }^{10}-$, there is no consensus on the amount of necessary resistance to increase strength in people with COPD ${ }^{11-13}$. López-García et al. ${ }^{14}$ and Elmorsi et al. ${ }^{15}$ suggested a load of 30 to $60 \%$ of the maximal inspiratory pressure (MIP) that should be adjusted according to patients' tolerance.

Previous studies demonstrated that the short-time low frequency IMT in COPD patients increases respiratory muscle ${ }^{11,12}$. However, its effects on reducing accessory inspiratory muscle activity remains unclear. Thus, this study aims to assess the effect of short inspiratory muscle training of low frequency on inspiratory muscle strength and electromyography activity of the SCM muscle in people with COPD attending a pulmonary rehabilitation program.

\section{METHODOLOGY}

This was a randomized controlled trial with blinded outcome rater. The trial was registered a priori at 
ClinicalTrials.gov (NCT02014155). The study was conducted at the lung rehabilitation program of the Santa Cruz do Sul Hospital, Brazil.

COPD patients at the stages II to IV, according to the Global Initiative for Chronic Obstructive Lung Disease (GOLD) classification ${ }^{1}$, participating in a lung rehabilitation program for at least 2 months, participant that were clinically stable and signed the informed consent were eligible to participate in the study. Individuals with asthma, and/or cardiovascular disease and individuals with cognitive and/or behavioral impairments were excluded.

Eligible participants were randomly allocated to intervention (IMT group) or control (control group) using a sealed opaque envelop. Participants allocated to the control group did not receive any additional intervention apart from participating in the lung rehabilitation program. Participants allocated to the IMT group participated in the same lung rehabilitation program, also receiving inspiratory muscle training using Threshold IMT ${ }^{\circledR}$ (Respironics ${ }^{\circledR}$, USA). The primary outcome was electromyography activity of the SCM muscle and the secondary outcome was inspiratory muscle strength in people with COPD attending a pulmonary rehabilitation program. Outcomes were measured in both groups in the pre and post short inspiratory muscle training of low frequency.

The intervention protocol for the IMT group was performed in three phases: (1) Pre-training assessment of maximal inspiratory pressure and pulmonary volumes, and electromyographic activity of the ECM muscle; (2) Education and training, participants received 3 sessions (20 minutes each) of training for familiarization with the Threshold IMT device without resistance for one week, followed by inspiratory muscle training 3 times a week for 20 minutes over 4 weeks, which was increased to 25 minutes on weeks 5 and 6 , and to 30 minutes on weeks 7 and 8 . Participants received a total of 24 sessions conducted by blinded personnel for the study objectives, and all sessions were supervised by a registered physiotherapist. (3) Posttraining: reassessment of maximal inspiratory pressure and electromyographic activity of the SCM muscles ${ }^{16}$. Threshold IMT was set at 50\% of maximal inspiratory pressure (assessed at baseline using a manometer). The device was adjusted weekly to increase the resistance for incremental strengthening training ${ }^{16}$.

The lung rehabilitation program included 30 minutes of cycling exercise on a vertical cycle ergometer for lower limbs (Movement ${ }^{\circledR}$, BM 2700, Brazil) set at $60 \%$ of the maximal heart rate determined using the Karvonen method modified for the reserve heart rate ${ }^{17}$. Participants also preformed strengthening exercises for major muscles of the upper and lower limbs, with the intensity of 50-80\% of the one repetition maximum test (1RM). Furthermore, a Borg scale was used to quantify the levels of dyspnea perceived by COPD patients.

Spirometry was used to classify disease stage according to the GOLD classification ${ }^{1}$. A spirometer (EasyOne ${ }^{\circledR}$, Modelo 2001, Switzerland) was used to assess forced vital capacity (FVC), forced expiratory volume in one second $\left(\mathrm{FEV}_{1}\right)$, forced expiratory flow between 25 and $75 \%$ of the $\mathrm{FVC}\left(\mathrm{FEF}_{25-75 \%}\right)$ and $\mathrm{FEV}_{1} / \mathrm{FVC}$ ratio expressed as the predicted values ${ }^{18}$. Spirometry values were compared to previously published and validated values ${ }^{19}$.

The assessment of inspiratory muscle strength followed the American Thoracic and European Respiratory Society protocol ${ }^{6}$. Participants were in sitting position and instructed to exhale, reaching the residual volume and inhale reaching the total lung capacity, to measure maximal inspiratory pressure. A total of five measurements were obtained, the two first were for learning purposes and the highest value from the following three was selected.

For the electromyography assessment, surface electrodes were used (MIOTEC ${ }^{\circledR}$, miotool400, Brazil) with a sample frequency of $2000 \mathrm{~Hz}$ per channel by circular bipolar electrodes (Meditrace 100 pediatric - $\mathrm{Ag} / \mathrm{AgCl}$ - solid gel sticker and conduction; Tyco Healthcare Group Canada Inc, Pointe Claire, Canada) at $15 \mathrm{~mm}$, pre-amplified and connected to a surface differential sensor (SDS500 model; Miotec Equipamentos Biomédicos Ltda., Brazil) with $30 \mathrm{~mm}$ distance between the electrodes center. The sensors were calibrated and the area was shaved and disinfected, before the assessment, with alcohol to remove dead skincells and reduce skin resistance to the electromyographic signal, as recommended by the International Society of Electrophysiology and Kinesiology ${ }^{20}$.

Participants were asked to laterally rotate the neck to the left during the evaluation of the SCM muscle, so that the muscle belly was better exposed, then, two electrodes were positioned $3 \mathrm{~cm}$ above the muscle belly. The percentage of root mean square (\%RMS) was obtained with the participant in sitting position assessing SCM muscle activation in two moments: (1) mean RMS\% of five respiratory incursions, and (2) the best of three maximal voluntary ventilation through the nose ${ }^{3}$. Then, data were exported to SAD 32 program (Laboratory 
of Mechanical Measures of the Universidade Federal do Rio Grande do Sul) for digital filtering.

\section{SAMPLE SIZE ESTIMATION AND STATISTICAL ANALYSES}

The sample size estimation was based on data obtained from the first five participants using the $G^{*}$ Power software (version 3.1.9.2) ${ }^{21,22}$. A total of ten participants were required in each group to detect a mean statistical difference of $22.4 \%$ on RMS electromyographic activity of SCM between groups with 10.8\% RMS standard deviation, $80 \%$ power and $5 \%$ significance level, and allowing for a $20 \%$ loss to follow-up.

Data analyses were performed using the software SPSS (version 20.0). Means and standard deviations (SD) or medians and interquartile ranges (IQR) are presented according to data normality. Shapiro-Wilk test was used to verify data distribution. Chi-squared test was used to compare gender proportions between groups. For intra group comparisons, paired Student's t test or MannWhitney U test for the non-parametric data, were used.
Moreover, analysis of covariance (ANCOVA) was used as a supportive analysis, to compare differences between groups after the intervention, adjusting for values of the respective outcomes at baseline ${ }^{23}$. A significance level of $5 \%$ was set for all analyses.

\section{RESULTS}

A total of 22 participants were randomly allocated to IMT group $(n=12)$ and control group $(n=10)$. Recruitment occurred between March and September 2014. Follow-up assessments were completed on October 2014. Two participants from the IMT group were lost to follow-up due to an acute worsening of the condition and lack of treatment adherence (Figure 1). No between-group difference was presented for the anthropometric characteristics or lung function at baseline (Table 1). Participants in both groups presented obstructive and restrictive patterns of lung function values. Participants from both groups did not present resting dyspnea.

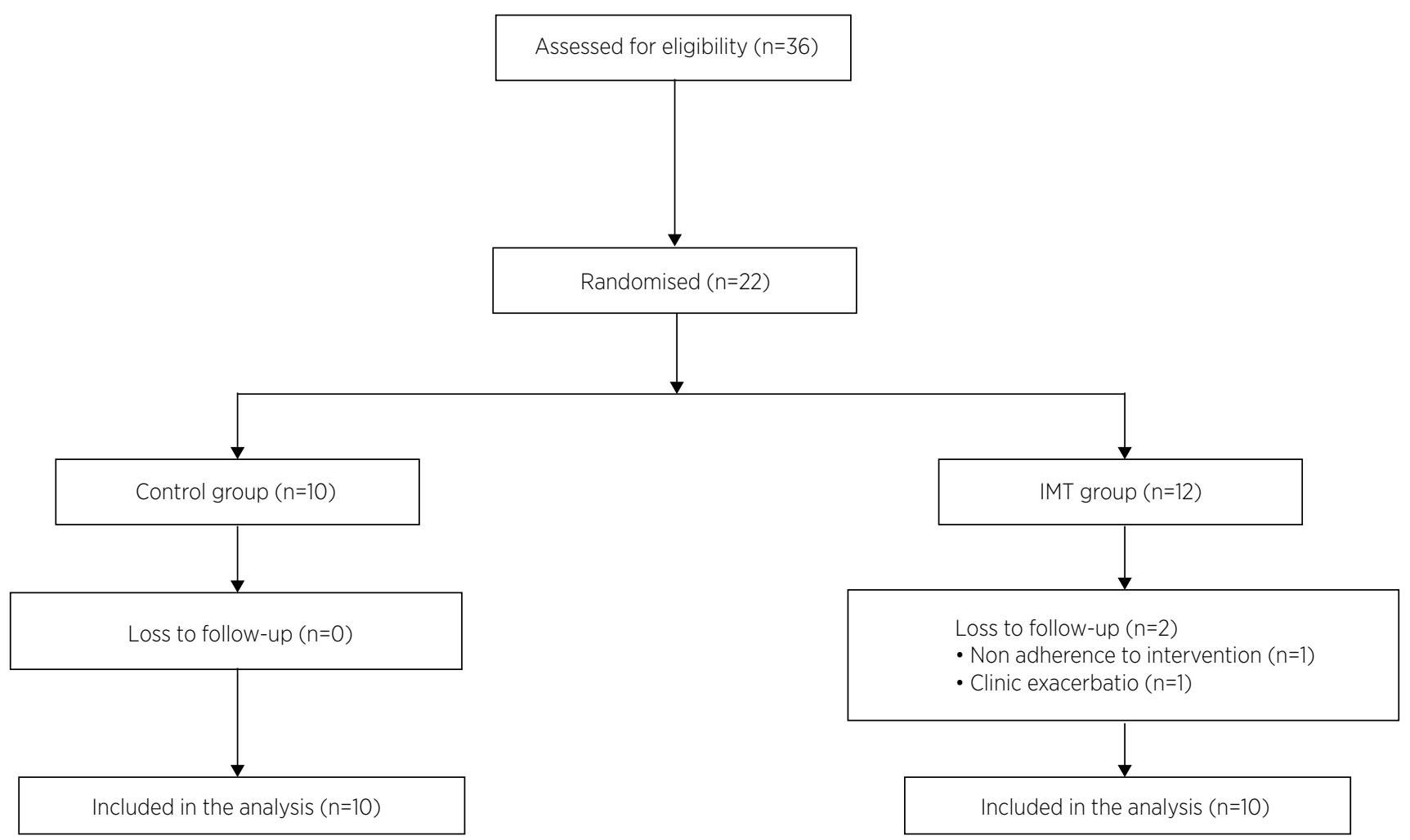

Figure 1. Study flow chart 
Table 1. Baseline characteristics of the included participants presented in means (standard deviation), unless otherwise stated

\begin{tabular}{|c|c|c|}
\hline Characteristic & Control group $(n=10)$ & IMT group $(n=10)$ \\
\hline Age (years) & $66.2(9.2)$ & $63.2(5.7)$ \\
\hline Sex, n female/male & $4 / 6$ & $5 / 5$ \\
\hline Weight (Kg) & $63.4(15.3)$ & $64.5(12.8)$ \\
\hline Height (m) & $1.5(0.1)$ & $1.6(0.1)$ \\
\hline $\mathrm{BMI}\left(\mathrm{Kg} / \mathrm{m}^{2}\right)$ & $25.4(5.8)$ & $25.3(5.1)$ \\
\hline FVC, \%predicted & $60(19)$ & $58(19.9)$ \\
\hline $\mathrm{FEV}_{1}$ \% \%redicted & $36(18.7)$ & $41(22.4)$ \\
\hline FEV $/$ /FVC, \%predicted & $59(20.4)$ & $68(22.9)$ \\
\hline $\mathrm{FEV}_{25-75 \%}, \%$ predicted & $13(9-22)$ & $23.3(8-35)$ \\
\hline $\operatorname{MIP}\left(\mathrm{cmH}_{2} \mathrm{O}\right)^{*}$ & $70(24.2)$ & $77.8(21.2)$ \\
\hline Female & $72.3(3)$ & $72.2(16.8)$ \\
\hline Male & $84.8(19.7)$ & $93.3(14.9)$ \\
\hline MIP (\%predicted) & $71(24)$ & $87.6(18.1)$ \\
\hline Female & 85.6 (11.9) & $82.7(7)$ \\
\hline Male & $85.9(18.3)$ & $98.7(11.7)$ \\
\hline
\end{tabular}

BMI: body mass index; FVC: forced vital capacity; FEV; forced expiratory volume during the first second; FEV $_{25-75 \%}$ : forced expiratory volume between 25 and $75 \%$ of the FVC; MIP: maximal inspiratory pressure. Data expressed as mean (standard deviation) and median (interquartile range). ${ }^{*}$ : mean and standard deviation of MIP of both sexes.

After the intervention with Threshold IMT, maximal inspiratory pressure was significantly higher for absolute $(\mathrm{p}<0.001)$ and predicted values $(\mathrm{p}<0.001)$ in the IMT group. The same effect was not observed on the control group ( $\mathrm{p}=0.710$ for absolute and $\mathrm{p}=0.162$ for predicted values). Furthermore, MIP increase is demonstrated when comparing pre and post intervention variation $(\Delta)$ between control and IMT Group for absolute $(p=0.001)$ and predicted values $(\mathrm{p}=0.011)$ (Table 2$)$.

At pre-training phase, IMT group presented a median (interquartile range) of $22.02 \% \mathrm{RMS}$ (10.58 to 32.09 ) and the control group presented a median of $26.74 \% \mathrm{RMS}$ (18.77 to 34.38), considering SCM muscle assessment. At post-training phase, for the SCM muscle assessment, IMT group presented a median of $6.38 \% \mathrm{RMS}$ (4.14 to 8.91 ) and the control group 34.08\%RMS (3.13 to 62.43). A significant decrease occurred in the activity of SCM muscles for the IMT group ( $\mathrm{p}=0.008)$, whereas the same effect was not observed in the control group. Regarding the SCM muscle, a difference between groups was observed, also favoring IMT group (mean difference between groups: $-16.6 \%$ RMS, $95 \%$ confidence interval: -31 to -2.1$)(\mathrm{p}=0.021)$ (Figure 2).

Table 2. Inspiratory muscle strength before and after intervention in control and IMT groups.

\begin{tabular}{|c|c|c|c|c|c|c|c|}
\hline \multirow[b]{2}{*}{ Characteristic } & \multicolumn{3}{|c|}{ Control group } & \multicolumn{3}{|c|}{ IMT group } & \multirow[b]{2}{*}{$\begin{array}{l}\text { Difference between } \\
\text { groups }(95 \% \mathrm{Cl}) \text { p-value* }\end{array}$} \\
\hline & Before & After & $\begin{array}{c}\text { Difference } \\
\text { between groups } \\
\text { p-value }\end{array}$ & Before & After & $\begin{array}{c}\text { Difference } \\
\text { between groups } \\
\text { p-value }\end{array}$ & \\
\hline $\mathrm{MIP}\left(\mathrm{cmH}_{2} \mathrm{O}\right)$ & $70(24.2)$ & 70.7 (24.0) & 0.710 & $77.8(21.2)$ & $95.12(20.5)$ & $<0.001$ & $\begin{array}{r}-16.6(-25.8 \text { to }-7.4) \\
0.001\end{array}$ \\
\hline $\begin{array}{l}\text { MIP (\% } \\
\text { predicted) }\end{array}$ & $71(24)$ & $87.4(42)$ & 0.162 & 87.6 (18.1) & $132.7(43.7)$ & $<0.001$ & $\begin{array}{r}-21.6(-37.6 \text { to }-5.7) \\
0.011\end{array}$ \\
\hline
\end{tabular}

MIP: maximal inspiratory pressure; IMT: inspiratory muscle training. Data presented as means (standard deviation). Cl: confidence interval. *: comparison between groups. p<0.05 was considered to be significant. Intragroup comparison: paired Student t test, or Mann-Whitney U test for the non-parametric data. Comparison between group: ANCOVA.

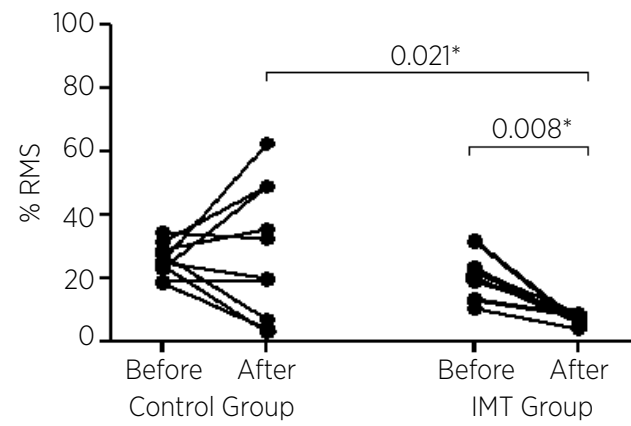

Figure 2. Medians and interquartile ranges of the percentage root mean square (\%RMS) on sternocleidomastoid muscle before and after intervention on control and IMT groups $(p<0.05)$

\section{DISCUSSION}

This study showed that inspiratory muscle training at $50 \%$ of the maximal inspiratory pressure with weekly adjustments of short-time low frequency training significantly increased maximal inspiratory pressure. The increase was observed on the pre-post changes and between-group variation of the IMT group. Furthermore, a reduction of the electromyography activity of the SCM muscle was verified. At the end of the study, the IMT group presented a mean of $95.12 \mathrm{cmH}_{2} \mathrm{O}$, exceeding the maximum load of $41 \mathrm{cmH}_{2} \mathrm{O}$ of the Threshold IMT as $50 \%$ of load (Table 2), which occurred only in the last week of training.

The beneficial effects of Threshold IMT on strength gains of inspiratory muscles in people with COPD have been reported previously in the literature ${ }^{14,24}$. It has been suggested that people with COPD should undergo training with IMT using loads between 40 and $50 \%$ of the maximal inspiratory pressure for 30 minutes a day, 5 days per week ${ }^{15}$. Moreover, it has been recommended 
weekly readjust of load to account for the changes on the inspiratory pressures ${ }^{15}$. Although there is no consensus on the optimal frequency or length of treatment, many specialists recommend a high frequency of training, usually performed daily ${ }^{25,26}$.

Despite the fact that Threshold IMT is widely used in COPD patients with inspiratory muscle weakness ${ }^{14,24}$, patients evaluated in the present study, regardless of gender, did not present such impairment, considering inspiratory muscle weakness as the reduction of absolute MIP lower than $50 \%$ of predicted value ${ }^{25}$. We chose this population because the primary focus to observe whether the short-term inspiratory muscle training would be able to reduce sternocleidomastoid muscle activation in individuals without inspiratory muscle weakness.

The present study showed an increase in the maximal inspiratory pressure and a significant reduction in SCM muscle activation in the IMT group after treatment, also when comparing the variation between groups. In healthy individuals, SCM is recruited only after $70 \%$ of the tidal volume has been reached, when the inspiratory capacity is increased by hypercapnia ${ }^{27}$ or hyperpnoea ${ }^{28}$. Our study demonstrated a considerable SCM muscle activation in eupnea for both groups, with significant reduction in its activation following the intervention in the IMT group. Gama et al. ${ }^{29}$ have also shown a reduction on SCM muscle activation, however the effects were only observed immediately after the IMT and on healthy individuals.

The loss in inspiratory muscle strength observed in people with COPD occurs mainly for lung hyperinflation, which leads to changes in the thoracic cage and diaphragm, lowering the hemidiaphragm and shortening its muscle fiber, leading the diaphragm to work in a disadvantaged area of the length-tension curve ${ }^{30}$.

Regarding the reduced SCM muscle activation observed at post intervention in the IMT group, it could be possibly explained by an improvement on the inspiratory muscle synergy, reducing the activation load of the muscles who are highly required in people with $\mathrm{COPD}^{3}$. A previous study has shown a significant change in the external intercostal muscle fibers following intervention with Threshold IMT at 40 to $50 \%$ load of $\mathrm{MIP}^{31}$. Such response suggest that other muscles, apart from the SCM, also benefit from the increase in strength following training with Threshold IMT.

Some limitations of this study include the difficulty to maintain the orientation of the electrodes in relation to the muscle fibers and to control the interference of factors existing between the muscle assessed and the positioning of the electrode (i.e., variations in the amount of subcutaneous fat ${ }^{32}$ and cross-captures of the activation of adjacent muscles ${ }^{33}$ ). Furthermore, the degree of hyperinflation was not assessed in the study participants. Also, it was not possible to perform intention-to-treat analysis with two patients allocated to the IMT group, who were excluded from the study, since they presented clinical exacerbation and non-adherence to the study protocol, prior to the initiation of inspiratory muscle training proper.

\section{CONCLUSIONS}

As far as we know, this is the first study to demonstrate that a short-time training with low frequency Threshold IMT seems to be an efficient method to increase inspiratory muscle strength as well as to detect SCM muscle activation on electromyography in people with COPD. This study results demonstrate that this simple technique can be replicable in COPD patients attending a lung rehabilitation program.

\section{REFERENCES}

1. Global Initiative For Chronic Obstructive Lung Disease. Global Strategy for Diagnosis, Management, and Prevention of Chronic Obstructive Lung Disease. Fontana; 2018.

2. Cardoso DM, Fregonezi GAF, Jost RT, Gass R, Alberton CL, Albuquerque IM, et al. Acute effects of expiratory positive airway pressure (EPAP) on different levels in ventilation and electrical activity of sternocleidomastoid and parasternal muscles in Chronic Obstructive Pulmonary Disease (COPD) patients: a randomized controlled trial. Braz J Phys Ther. 2016;20(6):525-34. doi: 10.1590/bjpt-rbf.2014.0190

3. Hudson AL, Gandevia SC, Butler JE. The effect of lung volume on the co-ordinated recruitment of scalene and sternomastoid muscles in humans. J Physiol. 2007;584(Pt 1):261-70. doi: 10.1113/jphysiol.2007.137240

4. Sá RB, Pessoa MF, Cavalcanti AGL, Campos SL, Amorim C, Andrade AD. Immediate effects of respiratory muscle stretching on chest wall kinematics and electromyography in COPD patients. Respir Physiol Neurobiol. 2017;242:1-7. doi: 10.1016/j.resp.2017.03.002

5. Sinderby C, Beck J, Spahija J, Weinberg J, Grassino A. Voluntary activation of the human diaphragm in health and disease. J Appl Physiol. 1998;85(6):2146-58. doi: 10.1152/jappl.1998.85.6.2146

6. American Thoracic Society, European Respiratory Society. ATS/ ERS Statement on respiratory muscle testing. Am J Respir Crit Care Med. 2002;166(4):518-624. doi: 10.1164/rccm.166.4.518

7. Duiverman ML, Huberts AS, van Eykern LA, Bladder G, Wijkstra PJ. Respiratory muscle activity and patient-ventilator 
asynchrony during different settings of noninvasive ventilation in stable hypercapnic COPD: does high inspiratory pressure lead to respiratory muscle unloading? Int J Chron Obstruct Pulmon Dis. 2017;12:243-57. doi: 10.2147/copd.S119959

8. Tout R, Tayara L, Halimi M. The effects of respiratory muscle training on improvement of the internal and external thoracopulmonary respiratory mechanism in COPD patients. Ann Phys Rehabil Med. 2013;56(3):193-211. doi: 10.1016/j.rehab.2013.01.008

9. Paiva DN, Assmann LB, Bordin DF, Gass R, Jost RT, Bernardo Filho $\mathrm{M}$, et al. Inspiratory muscle training with threshold or incentive spirometry: which is the most effective? Rev Port Pneumol. 2014;S0873-2159(14)00096-8. doi: 10.1016/ j.rppnen.2014.05.005

10. Chuang HY, Chang HY, Fang YY, Guo SE. The effects of threshol dinspiratorymuscletraining in patients with chronic obstructive pulmonary (COPD) disease: a randomized experimental study. J Clin Nurs. 2017;26(23-24):4830-8. doi: 10.1111/jocn.13841

11. Langer D, Charususin N, Jácome C, Hoffman M, McConnell A, Decramer M, Gosselink R. Efficacy of a novel method for inspiratory muscle training in people with chronic obstructive pulmonary disease. Phys Ther. 2015;95(9):1264-73. doi: 10.2522/ ptj.20140245

12. Majewska-Pulsakowska M, Wytrychowski K, Rożek-Piechura $K$. The role of inspiratory muscle training in the process of rehabilitation of patients with chronic obstructive pulmonary disease._Adv Exp Med Biol. 2016;885:47-51. doi: 10.1007/5584_2015_194

13. Nikoletou D, Man WD, Mustfa N, Moore J, Rafferty G, Grant RL, et al. Evaluation of the effectiveness of a homebased inspiratory muscle training programme in patients with chronic obstructive pulmonary disease using multiple inspiratory muscle tests. Disabil Rehabil. 2016:38(3):250-9. doi: 10.3109/09638288.2015.1036171

14. López-García A, Souto-Camba S, Blanco-Aparicio M, et al. Effects of a muscular training program on chronic obstructive pulmonary disease patients with moderate or severe exacerbation antecedents. Eur J Phys Rehabil Med. 2016;52(2):169-75.

15. Elmorsi, AS, Eldosoky ME, Mohsen MAA, Shalaby NM, Abdalla DA. Effect of inspiratoty muscle training on exercise performance and quality of life in patients with chronic obstructive pulmonay disease. Egypt J Chest Dis Tuberc. 2016;65(1):41-6. doi: 10.1016/j.ejcdt.2015.10.006

16. Garcia S, Rocha M, Pinto P, Lopes AMF, Bárbara C. Inspiratory muscle training in COPD patients. Rev Port Pneumol. 2008;14(2):177-94. doi: 10.1016/S0873-2159(15)30229-4

17. Meyer FJ, Borst MM, Buschmann HC, Ewert R, Friedmann-Bette $\mathrm{B}$, Ochmann $\mathrm{U}$, et al. Exercise testing in respiratory medicine. Pneumologie. 2013;67(1):16-34. doi: 10.1055/s-0032-1325901

18. Pereira C, Sato T, Rodrigues SC. New reference values for forced spirometry in white adults in Brazil. J Bras Pneumol. 2007:33(4):397-406. doi: 10.1590/S1806-37132007000400008

19. Neder JA, Andreoni S, Lerario MC, Nery LE. Reference values for lung function tests. II. Maximal respiratory pressures and voluntary ventilation. Braz J Med Biol Res. 1999;32(6):719-27. doi: 10.1590/S0100-879X1999000600007

20. Hermens HJ, Freriks B, Disselhorst-Klug C, Rau G. Development of recommendations for SEMG sensors and sensor placement procedures. J Electromyogr Kinesiol. 2000;10(5):361-74. doi: 10.1016/S1050-6411(00)00027-4

21. Faul F, Erdfelder E, Lang A-G, Buchner A. G*Power 3: A flexible statistical power analysis program for the social, behavioral, and biomedical sciences. Behav Res Methods. 2007;39:175-91. doi: 10.3758/BF03193146

22. Faul F, Erdfelder E, Buchner A, Lang A-G. Statistical power analyses using $G^{*}$ Power 3.1: tests for correlation and regression analyses. Behav Res Methods. 2009;41(4):1149-60. doi: 10.3758/ BRM.41.4.1149

23. Vickers AJ, Altman DG. Analysing controlled trials with baseline and follow upmeasurements, BMJ. 2001;323:1123-4. doi: 10.1136/ bmj.323.7321.1123

24. Croitoru A, Bogdan MA. Respiratory muscle training in pulmonary rehabilitation. Pneumologie. 2013;62(3):166-71.

25. Charususin N, Gosselink R, Decramer M, McConnell A, Saey D, Maltais F, et al. Inspiratory muscle training protocol for patients with chronic obstructive pulmonary disease (IMTCO study): a multicentre randomised controlled trial. BMJ Open. 2013;3(8). doi: 10.1136/bmjopen-2013-003101

26. Gosselink R, De Vos J, van den Heuvel SP, Segers J, Decramer M, Kwakkel G. Impact of inspiratory muscle training in patients with COPD: what is the evidence? Eur Respir J. 2011;37(2):416-25. doi: 10.1183/09031936.00031810

27. Campbell EJ. The role of the scalene and sternomastoid muscles in breathing in normal subjects; an electromyographic study. J Anat. 1955;89(Pt 3):378-86.

28. Raper AJ, Thompson WT Jr, Shapiro W, Patterson JL Jr. Scalene and sternomastoid muscle function. J Appl Physiol. 1966;21(2):497-502. doi: 10.1152/jappl.1966.21.2.497

29. Gama AEF, Carvalho LA, Feitosa LA, Nascimento JF Jr, Silva MGNM, Amorim CF, et al. Acute effects of incremental inspiratory loads on compartmental chest wall volume and predominant activity frequency of inspiratory muscle. J Electromyogr Kinesiol. 2013;23(6):1269-77. doi: 10.1016/ j.jelekin.2013.07.014

30. Luce JM, Culver BH. Respiratory muscle function in health and disease. Chest. 1982;81(1):82-90. doi: 10.1378/chest.81.1.82

31. Ramirez-Sarmiento A, Orozco-Levi M, Güell R, Barreiro E, Hernandez N, Mota S, et al. Inspiratory muscle training in patients with chronic obstructive pulmonary disease: structural adaptation and physiologic outcomes. Am J Respir Crit Care Med. 2002;166(11):1491-7. doi: 10.1164/rccm.200202-0750C

32. Gandevia SC, McKenzie DK. Human diaphragmatic EMG: changes with lung volume and posture during supramaximal phrenic nerve stimulation. J Appl Physiol. 1986;60:1420-8. doi: 10.1152/jappl.1986.60.4.1420

33. Sinderby C, Friberg S, Comtois N, Grassino A. Chest wall muscle cross-talk in canine costal diaphragm electromyogram. J Appl Physiol. 1996;81:2312-27. doi: 10.1152/jappl.1996.81.5.2312 